\title{
Effectiveness of the antioxidants BHA and BHT in selected vegetable oils during intermittent heating
}

\author{
By John Tsaknis*, Stavros Lalas and Evangelia Protopapa \\ Technological Education Institution (TEI) of Athens, Department of Food Technology, \\ Ag. Spiridonos str., 12210, Athens, Greece \\ Fax: +30-1-5314874 \\ e-mail: jtsaknis@teiath.gr
}

\section{RESUMEN}

Eficacia de los antioxidantes BHA y BHT en aceites vegetales durante el calentamiento intermitente.

Se ha comparado el comportamiento del aceite de oliva al calentamiento con respecto al del aceite de maíz, el aceite de orujo y una mezcla al $50 \%$ de aceite de oliva y aceite de maíz. Los aceites fueron calentados intermitentemente durante dos horas al día a una temperatura de $175^{\circ} \mathrm{C} \pm 5^{\circ} \mathrm{C}$ durante cinco días consecutivos. Bajo tales condiciones tuvo lugar la descomposición térmica y oxidativa de los mismos.

En todos los aceites aumentaron el contenido en ácidos grasos libres, el índice de peróxido $E_{1}^{1 \%}$, a 232 y $270 \mathrm{~nm}$, los compuestos polares, el color y la viscosidad, mientras que el índice de yodo, el punto de humo, el contenido en ácidos grasos poliinsaturados y el contenido en tocoferoles disminuyeron.

Se estudió la eficacia del 3-terc-butil-4-hidroxianisol (BHA) y del butilhidroxitolueno (BHT) en una proporción de 200 ppm en el retraso de la deterioración de los aceites durante el calentamiento estático $\left(175 \pm 5^{\circ} \mathrm{C}\right)$, encontrándose que el $\mathrm{BHA}$ dió una ligera protección al aceite de orujo y que el BHT proporcionó alguna protección al aceite de maíz, en tanto que ambos antioxidantes fueron relativamente ineficaces en los otros aceites.

PALABRAS-CLAVE: Aceite de maíz - Aceite de oliva - Aceite de orujo - BHA - BHT - Calentamiento.

\section{SUMMARY}

Effectiveness of the antioxidants BHA and BHT in selected vegetable oils during intermittent heating.

The heating performance of olive oil was compared with that of corn oil, olive-residue oil and 50:50 mixture of olive oil and corn oil. The oils were heated intermittently for two hours per day at a temperature of $175 \pm 5^{\circ} \mathrm{C}$ for five consecutive days. Under such conditions thermal and oxidative decomposition of the oils takes place.

Free fatty acid content, peroxide values, $E_{1 \mathrm{~cm}}^{1 \%}$ at 232 and $270 \mathrm{~nm}$, polar compounds, colour and viscosity, of the oils all increased, whereas the iodine values, smoke points, polyunsaturated fatty acids content and tocopherol concentration decreased.

The effectiveness of butylated hydroxyanisole $(\mathrm{BHA})$ and butylated hydroxytoluene (BHT) at a rate of $200 \mathrm{ppm}$ in retarding the deterioration of oils during static heating (175 \pm $5^{\circ} \mathrm{C}$ ), was studied and it was found that $\mathrm{BHA}$ gave a slight protection to the olive-residue oil and the BHT gave some protection to the corn oil, while both antioxidants were relatively ineffective in the other oils.

KEY-WORDS: BHA - BHT - Corn oil - Heating - Olive oil - Oliveresidue oil.

\section{INTRODUCTION}

Olive oil is an important commodity in the daily diet of most people in the Mediterranean region. It is extracted from the fruit of olive tree, Olea europea. Its uniqueness among vegetable oils is that it can be consumed in crude form (called virgin olive oil). The term "olive-residue oil" applies to the oil obtained from the residue (remaining cake) after the mechanical extraction of the oil from the olives. The cake is coarsely ground, partially dried and extracted with a fat solvent, usually hexane, in a continuous or batch process, refined, bleached and deodorised in the refinery. Corn (maize) oil is the oil extracted from the cereal grain, Zea mays $L$.

The above oils were used in this study because of their major commercial role as frying oils in restaurants and fast food outlets as well as in the domestic market of Mediterranean countries. The mixture has been included because is common practice to mix such oils at home.

Deep-fat frying enhances the sensory properties of foods. However, repeated use of frying oils produces undesirable constituents that may pose health hazards (Tyagi and Vasishtha, 1996). During deep-frying, fats and oils are repeatedly used at elevated temperatures in the presence of air. This causes partial conversion of fats and oils to volatile chain-scission products, non-volatile oxidised derivatives, and dimeric, polymeric, or cyclic substances (Chang et al., 1978).

The chemical reactions taking place during deep oil frying differ from those which occur when the oil is heated continuously, thus reactions occurring in studies conducted with oils heated in the presence of air, with or without agitation, may not be representative of those of the same oils used under normal intermittent frying conditions (Landers and Rathman, 1981).

Butylated hydroxyanisole (BHA) and butylated hydroxytoluene (BHT) are commonly added to fats and oils to retard oxidative deterioration due to storage and heat. Recent studies have found lack of agreement on the effectiveness of antioxidants in 
retarding deterioration of oils during heating (Tyagi and Vasishtha, 1996). Besides this, there are numerous analytical and chromatographic methods for assessment of heating fat deterioration, but there is not an analytical technique that can evaluate heated fat quality. Most of these are tedious and time consuming. Therefore, it is important to have simple, objective methods for assessing heating fat quality.

This study investigates the changes in oil quality characteristics and fatty acid composition of the selected oils with and without antioxidants under frying conditions by a combination of the most effective analytical and instrumental methods.

\section{EXPERIMENTAL PART}

\subsection{Reference compounds and solvents}

The virgin olive oil, corn oil and olive-residue oil were obtained from the local market. The antioxidants BHA and BHT (analytical grade) obtained from Sigma Chemicals Company Co. (St. Louis, MO 63178, USA).

All reagents (analytical and HPLC grade) were obtained from Sigma Chemicals Company Co.. Standard solutions for the determination of tocopherols were purchased from Merck Ltd (Darmstand, D-64271, Germany) (dl- $\alpha$-tocopherol) and Sigma ((+)- $\delta$-tocopherol). Fatty acid methylesters standards were obtained from British Greyhound Chromatography and Allied Chemicals (Birkenhead, Merseyside, L434X, UK).

\subsection{Heating Experiment}

The method used for the heating experiment was adapted from Tsaknis (1991). Three series of heating experiments were carry out: (a) Oils only; (b) Oils and $0.02 \%$ w/w BHA; (c) Oils and $0.02 \%$ w/w BHT. Three litres of olive oil, corn oil, olive-residue oil and mixture of 50:50 olive oil and corn oil were heated at $175 \pm 5$ ${ }^{\circ} \mathrm{C}$ for two hours in four separate uncovered stainless steel frying pans. The oil temperatures were measured by thermocouples. The length of time required to heat the oils to this temperature was between 27 and 32 min. After 2 hours heating the frying pans were removed from the kitchen and left to cool at room temperature $\left(23^{\circ} \mathrm{C}\right)$. A $100 \mathrm{gr}$ sample was transferred to a $250 \mathrm{gr}$ glass bottle. Nitrogen was added and stored at $-20^{\circ} \mathrm{C}$. The lids of the fryers were replaced and the oils were left at room temperature overnight. The heating was continued the next day. This was repeated for a total of five days.

Each antioxidant, at a level of 200 ppm, was added directly to the oil and was mixed with the aid of a motor-driven glass stirrer for 30 minutes at $60^{\circ} \mathrm{C}$ to complete dissolution of the antioxidants. The temperature of the oil was then raised to $175 \pm 5^{\circ} \mathrm{C}$ without stirring.

\subsection{Determination of the physical and chemical characteristics}

Colour was measured according to the AOCS (1978) cc13c-50 method. Smoke point was determined according to the method described by British Standards Methods of Analysis (1976) (BS 684: Section 1.8). The viscosity was measured using a Brookfield viscometer at a temperature of $25^{\circ} \mathrm{C}$. Acidity (IUPAC, 1987), iodine value (Pearsons, 1981) and polar compounds (IUPAC, 1987) were also determined.

Methyl esters of fatty acids formed with $\mathrm{BF}_{3}$-Methanol reagent according to Tsaknis et al. (1999) method were injected into a Varian 3600 Gas Chromatograph (Varian, Palo Alto, California, USA) equipped with a Supelcowax 10 (Supelco, INC., Supelco Park, Bellefonte, PA 16823-0048, USA) fused silica capillary column $30 \times 0.32 \mathrm{~mm} \mathrm{ID,}$ $0.25 \mu \mathrm{m}$ film thickness. The temperature program was $60^{\circ} \mathrm{C}$ for $10 \mathrm{~min}$ and then $2^{\circ} \mathrm{C} / \mathrm{min}$ up to $220^{\circ} \mathrm{C}$. Injector and FID temperatures were set at $160^{\circ} \mathrm{C}$ and $280^{\circ} \mathrm{C}$ respectively, sample volume was $0.2 \mu \mathrm{l}$, and the carrier gas was $\mathrm{N}_{2}$ at a flow of $30 \mathrm{ml} / \mathrm{min}$. The internal standard used was nonadecanoic acid. Methyl esters were identified and quantified by comparing the retention times and peak area of the unknowns with those known FAME standard mixtures.

The method used for the determination of tocopherols was adapted from Tsaknis et al. (1999). $1 \mathrm{~g}$ of oil was accurately weighed into a 3 dram sample vial wrapped in aluminium foil to prevent oxidation. The oil was dissolved in a $5 \mathrm{ml} n$-hexane before injection. A $20 \mu \mathrm{l}$ sample was injected into the Waters 600E HPLC pump (Millipore Corporation, Waters Chromatography Division, Massachusetts, MA 01757, USA) fitted with a Waters $\mu$-Polarsil, $125 \AA$, $10 \mu \mathrm{m}, 3.9 \times 300 \mathrm{~mm}$ column. A Waters 486 Tunable Absorbance Detector was used set at 295 nm. Iso-propanol: n-hexane: absolute ethanol (2: 97.5: 0.5) at $1 \mathrm{ml} / \mathrm{min}$ was used as the mobile phase. A total of $5 \mathrm{~min}$ was necessary to assay the tocopherols. They were identified by comparing the retention times and quantified based on peak area percent of the unknowns with those of known standards. Samples were prepared and measured separately in triplicate.

For the determination of the oxidative state the peroxide value (Lea, 1952), as well as, the specific extinction (IUPAC, 1987) $\left(E_{1}^{1 \%} \mathrm{~cm}\right)$ at 232 and $270 \mathrm{~nm}$, was measured using a Hitachi U-3210 Spectrophotometer (Hitachi Ltd. Tokyo, Japan). The susceptibility to oxidation was determined by the Rancimat method (Laubli and Bruttel, 1986), and the determination was performed on a Metrohm Rancimat 679 (Metrohm Ltd., CH-9101, Herisau, Switzerland) at a temperature of $120^{\circ} \mathrm{C}$. 


\subsection{Statistical analysis}

Results are representing the average and the Standard Deviation (SD) (in parenthesis) of three simultaneous assays carried out in all methods. Statistical significance of the differences between mean values was assessed by ANOVA test.

\section{RESULTS AND DISCUSSION}

During determinations, all samples were evaluated while in Tables only initial and final data ( 0 and 10 hours) are displayed.

lodine value. Table I illustrates the changes in iodine value of heated oils. The results showed that there were not significant $(P<0.05)$ changes between the fresh and used oils after 5 days heating. The decrease of iodine value correlated well with the decrease of unsaturated fatty acids $(r=0.992)$, and more over this analysis confirmed that less oxidation of unsaturated fatty acids has taken place in olive oil. lodine value decreases are indicative of the increased rate of oxidation during heating and could be attributed to oxidation and polymerisation reactions involving the double bonds (Alim and Morton, 1974).

When the oils were heated in presence of BHA and BHT the same trend seemed to be followed, although the absolute values of lodine Value were slight lower compared with the same heated oils without antioxidants. No significant differences were observed in heated oils with and without antioxidants. The results suggest that both antioxidants were ineffective in limiting the oxidation of unsaturated fatty acids.

Peroxide value (PV). Table I illustrates the changes in peroxide value of heated oils. Olive oil and mixture oil did not show a significant increase of PV after 10 hours heating, whilst the olive-residue oil showed a significant increase $(P<0.05)$ after 10 hours heating and the corn oil after 8 hours heating. All the oils, except the mixture oil, showed an increase of PV during heating time. The mixture oil showed a decrease in PV at the initial stages of heating until $6 \mathrm{~h}$. Further heating resulted in a new increase in PV. Peroxides under the heating conditions used are unstable, and react to form secondary oxidation products. An increase in the initial stage of heating would be expected to be followed by a decrease with further heating, because the hydroperoxides tend to decompose at $180^{\circ} \mathrm{C}$ to form secondary oxidation products (Perkins, 1967). The overall increase in peroxide value is connected with the cooling period of the oil. The length of time required to cool the oils at room temperature $\left(28^{\circ} \mathrm{C}\right)$ was more than $4 \mathrm{~h}$. During the cooling period the oils were exposed to air at high temperature and hydroperoxides were formed again (Augustin and Berry, 1983).

Table I

Changes in iodine value, peroxide value, smoke point and acidity during heating of oils

\begin{tabular}{|c|c|c|c|c|c|c|c|c|}
\hline & Ohr heating* & 10hr heating & Ohr heating ${ }^{*}$ & 10hr heating & Ohr heating* & 10hr heating & Ohr heating ${ }^{*}$ & 10hr heating \\
\hline Oil & \multicolumn{2}{|c|}{ lodine value (g l/100 g of oil) } & \multicolumn{2}{|c|}{ Peroxide value (meq $\mathrm{O}_{2} / \mathrm{kg}$ of oil) } & \multicolumn{2}{|c|}{ Smoke point $\left({ }^{\circ} \mathrm{C}\right)$} & \multicolumn{2}{|c|}{ Acidity (\% as oleic acid) } \\
\hline Olive oil & $84.01 \pm 0.58$ & $83.13 \pm 1.12$ & $1.04 \pm 0.46$ & $5.10 \pm 1.37$ & $199 \pm 2.5$ & $194 \pm 1.0$ & $0.13 \pm 0.11$ & $0.27 \pm 0.19$ \\
\hline Corn oil & $126.35 \pm 0.80$ & $124.32 \pm 0.99$ & $1.41 \pm 0.62$ & $6.45 \pm 0.86$ & $223 \pm 1.5$ & $220 \pm 2.0$ & $0.14 \pm 0.07$ & $0.40 \pm 0.08$ \\
\hline Ol.r. oil** & $92.98 \pm 0.61$ & $91.47 \pm 1.07$ & $2.70 \pm 0.53$ & $6.21 \pm 0.78$ & $203 \pm 1.8$ & $199 \pm 2.5$ & $0.16 \pm 0.12$ & $0.36 \pm 0.10$ \\
\hline \multirow[t]{2}{*}{ Mixture oil } & $104.02 \pm 0.97$ & $102.83 \pm 1.15$ & $1.30 \pm 0.46$ & $6.45 \pm 1.20$ & $201 \pm 1.6$ & $197 \pm 1.2$ & $0.13 \pm 0.07$ & $0.28 \pm 0.14$ \\
\hline & lodine value $(\mathrm{g} / / 100 \mathrm{~g}$ of oil) of oil containing & $\begin{array}{l}\text { ill) of oil containing } \\
A A\end{array}$ & Peroxide value (meq $\mathrm{O}_{2} / \mathrm{kg}$ of oill) of oil & $\begin{array}{l}2 / \mathrm{kg} \text { of oill of oil } \\
\% \text { BHA }\end{array}$ & \multicolumn{2}{|c|}{ Smoke point $\left({ }^{\circ} \mathrm{C}\right)$ of oil containing $0.02 \% \mathrm{BHA}$} & Acidity (\% as oleic acid) of oil containin & $\begin{array}{l}\text { of oil containing } \\
\text { A }\end{array}$ \\
\hline Olive oll & $84.01 \pm 0.58$ & $83.20 \pm 0.75$ & $1.04 \pm 0.46$ & $3.69 \pm 1.25$ & $199 \pm 2.5$ & $195 \pm 1.25$ & $0.13 \pm 0.11$ & $0.24 \pm 0.13$ \\
\hline Corn oil & $126.35 \pm 0.80$ & $124.39 \pm 0.70$ & $1.41 \pm 0.62$ & $5.76 \pm 0.91$ & $223 \pm 1.5$ & $220 \pm 1.66$ & $0.13 \pm 0.07$ & $0.32 \pm 0.17$ \\
\hline Ol.r. $0 \|^{* \star}$ & $92.98 \pm 0.61$ & $91.51 \pm 0.73$ & $2.70 \pm 0.53$ & $6.44 \pm 0.98$ & $203 \pm 1.8$ & $199 \pm 1.89$ & $0.16 \pm 0.12$ & $0.33 \pm 0.18$ \\
\hline \multirow[t]{2}{*}{ Mixture oil } & $104.02 \pm 0.97$ & $102.86 \pm 0.59$ & $1.30 \pm 0.46$ & $5.03 \pm 1.08$ & $201 \pm 1.6$ & $198 \pm 2.45$ & $0.13 \pm 0.07$ & $0.28 \pm 0.10$ \\
\hline & lodine value ( $\mathrm{g} / / 100 \mathrm{~g}$ of oil) of oil containing & $\begin{array}{l}\text { ill) of oil containing } \\
\text { HT }\end{array}$ & Peroxide value (meq $\mathrm{O}_{2} / \mathrm{kg}$ of oill) of oil & $\begin{array}{l}2 / \mathrm{kg} \text { of oill of oil } \\
\% \text { BHT }\end{array}$ & \multicolumn{2}{|c|}{ Smoke point $\left({ }^{\circ} \mathrm{C}\right)$ of oil containing $0.02 \% \mathrm{BHT}$} & Acidity (\% as oleic acid) of oil containing & $\begin{array}{l}\text { of oil containing } \\
T\end{array}$ \\
\hline Olive oil & $84.01 \pm 0.58$ & $83.29 \pm 0.55$ & $1.04 \pm 0.80$ & $3.18 \pm 0.97$ & $199 \pm 2.5$ & $194 \pm 2.59$ & $0.13 \pm 0.11$ & $0.23 \pm 0.12$ \\
\hline Corn oil & $126.35 \pm 0.80$ & $124.48 \pm 0.68$ & $1.41 \pm 0.35$ & $5.24 \pm 0.88$ & $223 \pm 1.5$ & $220 \pm 2.94$ & $0.13 \pm 0.07$ & $0.31 \pm 0.10$ \\
\hline Ol.-r. oil & $92.98 \pm 0.61$ & $91.54 \pm 0.31$ & $2.70 \pm 1.04$ & $6.73 \pm 0.89$ & $203 \pm 1.8$ & $198 \pm 3.56$ & $0.16 \pm 0.12$ & $0.31 \pm 0.10$ \\
\hline Mixture oil & $104.02 \pm 0.97$ & $102.88 \pm 0.54$ & $1.30 \pm 0.52$ & $5.81 \pm 1.32$ & $201 \pm 1.6$ & $198 \pm 2.65$ & $0.13 \pm 0.07$ & $0.24 \pm 0.10$ \\
\hline
\end{tabular}


In view of these factors, peroxide value is not to be recommended for measuring frying oil deterioration. The method suggested by Tsaknis et al. (1998) would be more suitable for measuring frying oil deterioration, because it determines malondialdehyde, which is a stable secondary oxidation product. The heated oils containing the antioxidants BHA and BHT seemed to follow the same trend and no significant differences were observed in heated oils with and without antioxidants.

Smoke point. Table I illustrates the changes in smoke point of fresh and used for 10 hours heated oils. As expected a decrease of smoke point of the oils was observed but these changes were not significant $(P<0.05)$. The decrease of smoke point was noted to be the highest in olive oil $\left(5^{\circ} \mathrm{C}\right)$ and the lowest in corn oil $\left(3^{\circ} \mathrm{C}\right)$. Mixture and olive-residue oil had an equal decrease $\left(4^{\circ} \mathrm{C}\right)$. The decrease of smoke point in heated oils with BHA and BHT seemed to follow the same trend and was not significant. Morton and Chidley (1988) reported that the amount of smoke emanating from a cup is directly proportional to the concentration of low molecular weight decomposition products in the oil. The free fatty acids and other volatile substances leaving the fat as gases will not appear as smoke until their concentration is great enough to permit aggregation to colloidal sized particles.

Colour. Figure 1 illustrates the changes in colour content of oils. The results showed that the increase in colour was significant $(\mathrm{P}<0.05)$ in olive oil, mixture and olive-residue oil after 8 hours heating, while in corn oil the increase was significant $(P<0.05)$ after 6 hours heating. The increase of colour in heated with the $\mathrm{BHA}$ and $\mathrm{BHT}$ oils was similar to that of heating oils without antioxidants. Darkening is attributed to the presence of unsaturated carbonyl compounds which are intermediates to give non-volatile decomposition products containing carbonyl group and have the ability to absorb energy of the magnitude of visible light (Gutierrez et al., 1988).

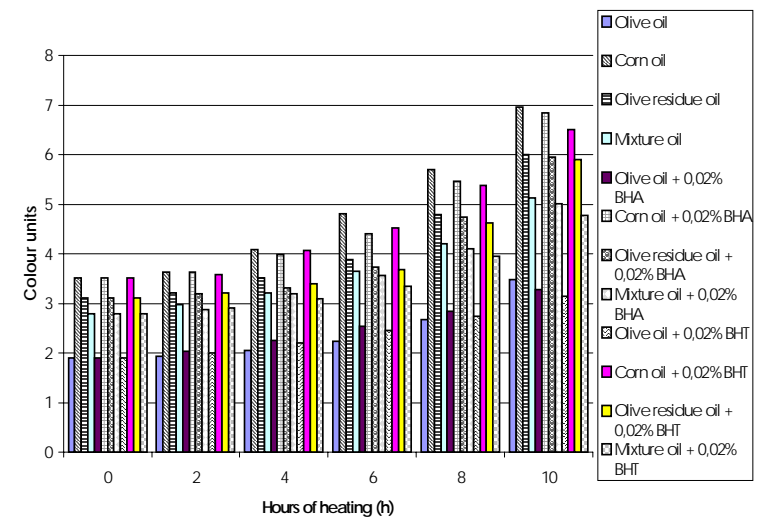

Figure 1

Changes in colour during heating of oils.

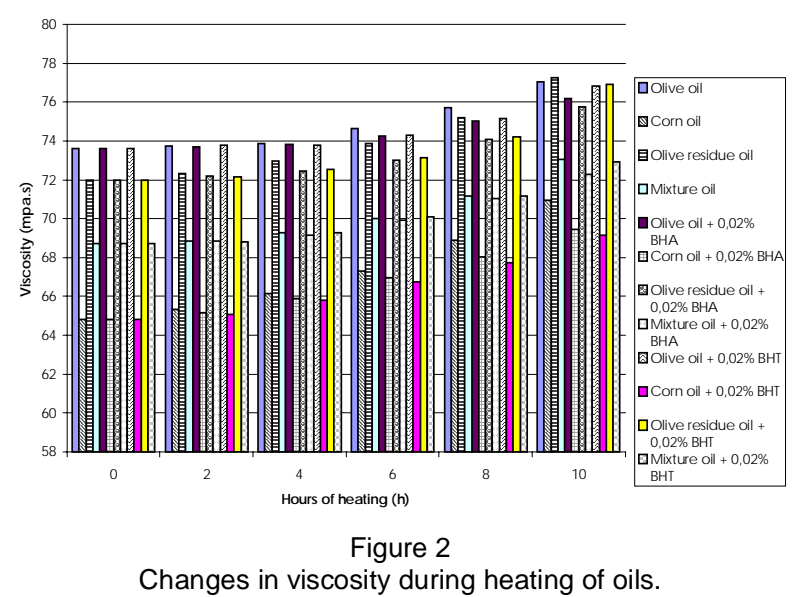

Viscosity. Figure 2 illustrates the changes in viscosity of fresh and used for 10 hours heated oils. The results showed that the increases in viscosity was significant $(P<0.05)$ in olive oil after 10 hours heating, in mixture oil after 8 hours heating and in olive-residue and corn oil after 6 hours of heating. $\mathrm{BHA}$ gave some protection to the olive-residue oil, which presented no significant increase in viscosity after 6 hours heating, while the same oil showed significant increase at the same time, when was heated without BHA. BHT gave some protection to the corn oil and after 6 hours heating the viscosity was not significant. As the oxidation is accelerated by heat proceeded, the values of viscosity progressively increased (Tyagi and Vanishita, 1996). These results clearly indicated the higher deteriorative effect of oxidation and polymerisation of corn and olive-residue oil compared to olive and mixture oil. The increase in viscosity of heating oils was due to polymerisation that resulted in formation of higher molecular weight compounds (carbon to carbon and/or carbon to oxygen-to carbon bridges) between fatty acids (Al-Harbi and Al-Kabtani, 1993).

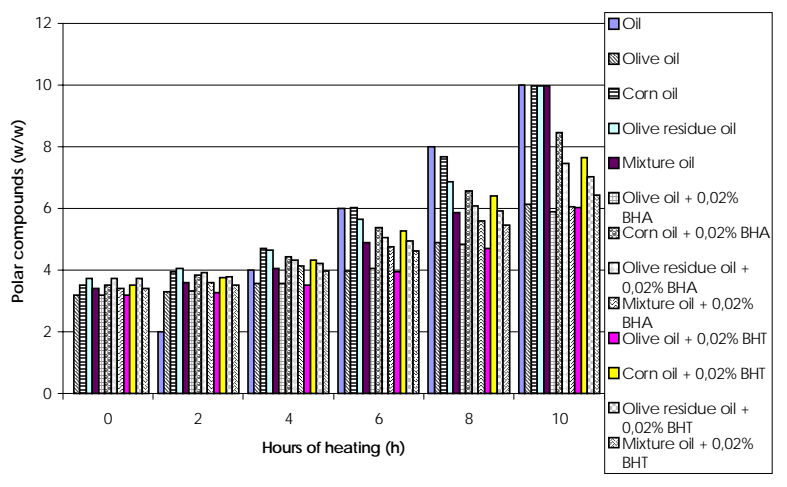

Figure 3

Changes in polar compounds during heating of oils. 
Polar compounds. Figure 3 shows the changes in polar compounds of fresh and used for 10 hours heated oils. The increase in polar compounds was significant $(P<0.05)$ in olive oil after 10 hours heating, in mixture oil and olive-residue oil after 8 hours of heating and in corn oil after 6 hours of heating. The results demonstrated that olive oil exhibited the lowest increase in polar compounds, while the corn oil the highest. The increase BHA and BHT had an improving effect on the polar compounds of corn oil and showed no significant increase after 6 hours heating, while the same oil showed significant increase when it was heated without BHA and BHT. Both the antioxidants did not appear to control the increase of the polar compounds in the other heated oils. Fritch (1981) reported that the analysis of percentage polar compounds is considered to be one of the more reliable indicators of the state of the oil deterioration. This latter statement is supported by those of other research workers (Gutierrez et al., 1988).

Free fatty acid (FFA) content (Acidity). Table I illustrates the changes in free fatty acids of heating oils. A slight but not significant increase $(\mathrm{P}<0.05)$ was observed after 5 days of heating in all the oils at the $95 \%$ level of significance (student's t-test). Olive oil showed the lowest increase and corn oil the highest. The increase in FFA could be attributed to oxidation and hydrolysis that produces FFA. As no water was added to the oil during heating, it may be concluded that the glycerides reacted with water that was formed by oxidation products and free radicals (Abdel-Aal and Karara, 1986; Peeled et al., 1975). Moreover, fatty acid content is a dynamic value, since at the same time that the acids are being produced they have sufficient vapour pressure at frying temperatures to evaporate from the surface (Peeled et al., 1975). However, though acidity is commonly used as an indicator of oil quality, it should not be relied upon as the sole measure.

The increase in FFA of the heated with BHA and $\mathrm{BHT}$ oils, was similar to that obtained without

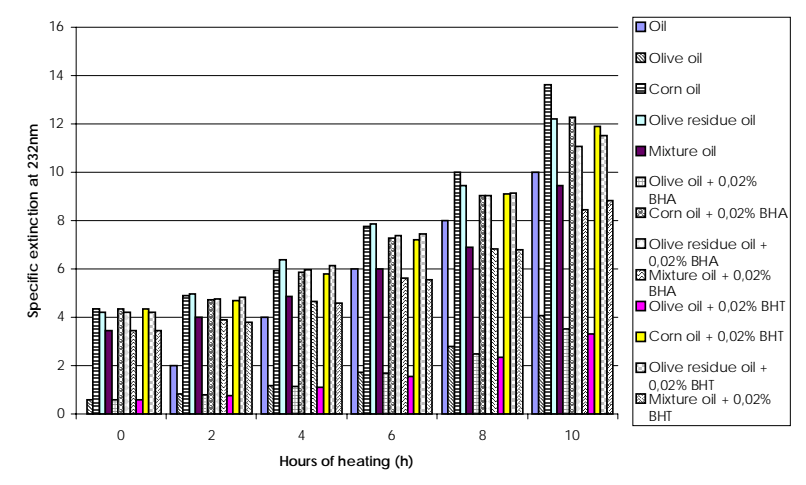

Figure 4

Changes in specific extintion at $232 \mathrm{~nm}$ during heating of oils.

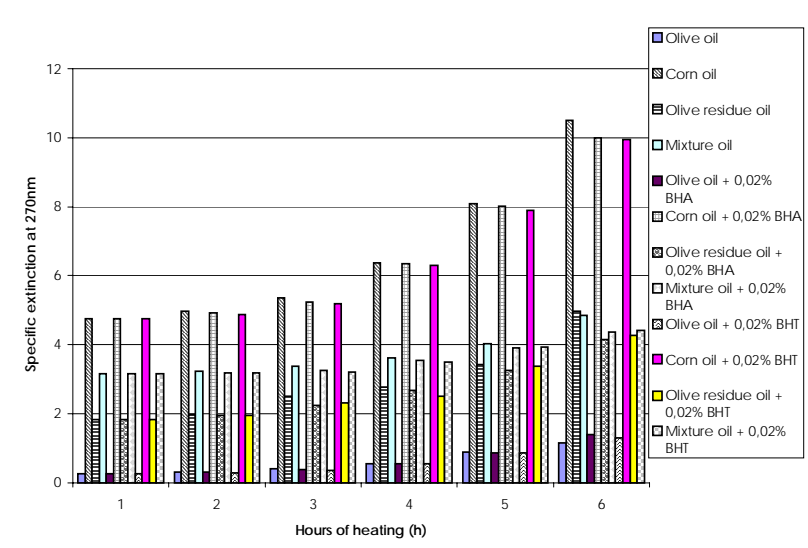

Figure 5

Changes in specific extinction at $270 \mathrm{~nm}$ during heating of oils.

antioxidants heated oils, confirming that, $\mathrm{BHA}$ and $\mathrm{BHT}$ has no retardatory effect on oil deterioration.

Specific extinction $\left(E_{1 \% \mathrm{~m},}^{1}\right)$ at 232 and $270 \mathrm{~nm}$. Figures 4 and 5 show the changes in specific extinction at 232 and $270 \mathrm{~nm}$ of used oils. The specific extinction at $232 \mathrm{~nm}$ which measures the degree of the primary oxidation products and the specific extinction at $270 \mathrm{~nm}$ which measures the degree of secondary oxidation products, increased during heating time and was significant $(P<0.05)$ after 2 hours of heating in all the used oils with and without antioxidants.

Fame analysis by gas chromatography. Table II illustrates the changes in fatty acid composition of heated oils. The results showed that after 10 hours heating the saturated fatty acid content of all four oils increased as the polyunsaturated fatty acid (PUFA) content decreased. However, this decrease was not significant $(P<0.05)$. The monounsaturated fatty acid content remained practically unchanged after 10 hours heating. The loss of linoleic acid was noted to be the highest in corn oil and the lowest in olive oil. The decrease of linoleic acid in the heated oils containing $\mathrm{BHA}$ and $\mathrm{BHT}$ and in heated oils without

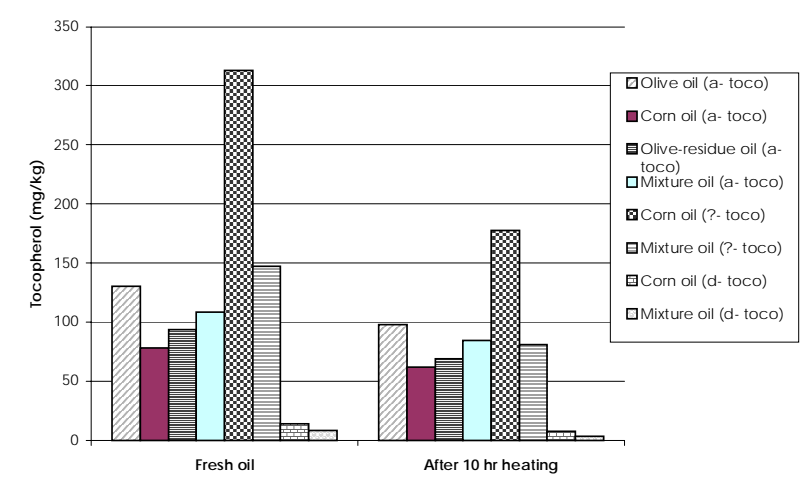

Figure 6

Changes of tocopherols in fresh and heated oils. 


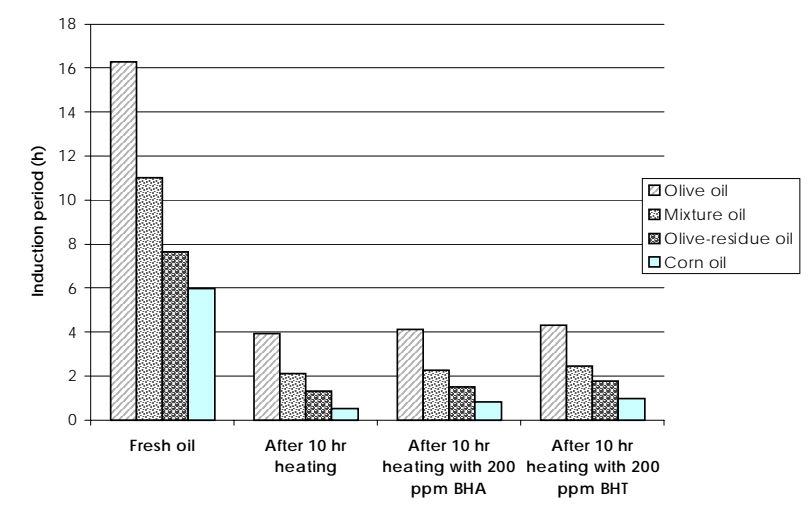

Figure 7

Changes in induction period.

antioxidants were as follows: $0.79,0.68$ and 0.85 for the olive oil, 1.18, 1.12 and 1.23 for mixture oil, 1.24, 1.26 and 1.39 for the olive-residue oil and $1.85,1.73$ and 1.97 for the corn oil respectively. The differences in the absolute values showed that both antioxidants had a slight retardatory effect on oil oxidation.

HPLC of tocopherols. Figure 6 illustrates the changes in tocopherols of heated oils. The relative decomposition rates after 10 hours of heating were delta $>$ gamma $>$ alpha. Significant changes of the tocopherol content were observed $(P<0.05)$ after the $1^{\text {st }}$ day. The results are in agreement with those of Sonntag (1979) who reported that the decomposition rates of tocopherols, after 10 hours heating, were gamma > alpha. Lea (1960) showed that the order of antioxidant activity changed with the oil used for the experiment. In contrast Miyagawa (1991) in their experiments, using a mixture of soybean and rapeseed oils, found that the decomposition rates of tocopherols were gamma > delta > alpha after 32 batches of frying. The reduction of tocopherols in heated with the BHA and BHT oils was similar to that of heating oils without antioxidants.

Induction Period. Figure 7 illustrates the changes in induction period of heated with and without antioxidants oils, as well as the protection factors of the antioxidants $\mathrm{BHA}$ and $\mathrm{BHT}$. The results showed that $\mathrm{BHA}$ offered some protection in the corn oil (PF 1.50) and olive residue oil (PF 1.15) and the lowest protection in the olive oil (PF 1.05) and mixture oil (PF 1.06). BHT offered some protection in the corn oil (PF 1.78), while it was quite ineffective in the other oils. The induction period determined via accelerated oxidation methods on the original oil cannot guarantee or predict the actual frying performance of the oil as other factors will be introduced once frying commences (e.g. badly operated fryer or heat exchanger will ruin even the best quality oil). Nevertheless, it is considered that the "Rancimat" induction period can be useful to act as a "screening" test and eliminate the possibility of introducing lower stability oils into the production area with all the attendant consequences(Morton and Chidley, 1988).

Table II

Fatty acid composition (\% wt) of heated olive oil, corn oil, olive-residue oil and mixture oil

\begin{tabular}{|c|c|c|c|c|c|c|c|c|}
\hline Fatty acid & Ohr heating ${ }^{\star}$ & 10hr heating & Ohr heating ${ }^{*}$ & 10hr heating & Ohr heating ${ }^{*}$ & 10hr heating & Ohr heating ${ }^{\star}$ & 10hr heating \\
\hline & \multicolumn{2}{|c|}{ Olive oil } & \multicolumn{2}{|c|}{ Corn oil } & \multicolumn{2}{|c|}{ Olive-residue oil } & \multicolumn{2}{|c|}{ Mixture oil (50:50 olive oil and corn oil) } \\
\hline C16:0 & $11.19 \pm 0.35$ & $11.68 \pm 0.20$ & $10.63 \pm 0.76$ & $11.90 \pm 0.34$ & $10.18 \pm 0.78$ & $11.00 \pm 0.27$ & $11.06 \pm 0.99$ & $11.68 \pm 0.58$ \\
\hline C16:1 & $1.22 \pm 0.71$ & $1.17 \pm 0.61$ & - & & $0.70 \pm 0.38$ & $0.74 \pm 0.21$ & $0.64 \pm 0.36$ & $0.63 \pm 0.45$ \\
\hline C18:0 & $2.33 \pm 0.51$ & $2.57 \pm 0.31$ & $1.67 \pm 0.31$ & $2.34 \pm 0.19$ & $2.70 \pm 0.69$ & $3.01 \pm 0.48$ & $2.12 \pm 0.91$ & $2.47 \pm 0.59$ \\
\hline C18:1 & $74.53 \pm 0.82$ & $74.62 \pm 0.52$ & $29.20 \pm 0.67$ & $29.32 \pm 0.24$ & $70.02 \pm 0.82$ & $70.15 \pm 0.64$ & $51.30 \pm 0.32$ & $51.40 \pm 0.43$ \\
\hline C18:2 & $8.82 \pm 0.79$ & $7.97 \pm 0.82$ & $55.80 \pm 0.62$ & $53.83 \pm 0.75$ & $14.56 \pm 0.78$ & $13.17 \pm 0.60$ & $32.48 \pm 0.69$ & $31.25 \pm 0.28$ \\
\hline \multirow[t]{2}{*}{ C18:3 } & $1.12 \pm 0.40$ & $0.94 \pm 0.51$ & $1.86 \pm 0.61$ & $1.63 \pm 0.15$ & $1.28 \pm 0.46$ & $1.03 \pm 0.24$ & $1.48 \pm 0.61$ & $1.33 \pm 0.45$ \\
\hline & \multicolumn{2}{|c|}{ Olive oil $+0.02 \%$ BHA } & \multicolumn{2}{|c|}{ Corn oil $+0.002 \% B H A$} & \multicolumn{2}{|c|}{ Olive-residue oil $+0.02 \% B H A$} & \multicolumn{2}{|c|}{ Mixture oil (50:50 olive oil and corn oil) $+0.02 \% \mathrm{BH}$} \\
\hline C16:0 & $11.19 \pm 0.34$ & $11.61 \pm 0.31$ & $10.63 \pm 0.68$ & $11.82 \pm 0.25$ & $10.18 \pm 0.76$ & $10.90 \pm 0.31$ & $11.06 \pm 0.99$ & $11.60 \pm 0.33$ \\
\hline C16:1 & $1.22 \pm 0.72$ & $1.17 \pm 0.90$ & - & - & $0.70 \pm 0.39$ & $0.63 \pm 0.21$ & $0.64 \pm 0.36$ & $0.62 \pm 0.21$ \\
\hline C18:0 & $2.33 \pm 0.59$ & $2.57 \pm 0.16$ & $1.67 \pm 0.31$ & $2.30 \pm 0.25$ & $2.70 \pm 0.70$ & $3.15 \pm 0.43$ & $2.12 \pm 0.91$ & $2.47 \pm 0.20$ \\
\hline C18:1 & $74.53 \pm 0.82$ & $74.68 \pm 0.22$ & $29.20 \pm 0.68$ & $29.30 \pm 0.31$ & $70.02 \pm 0.83$ & $70.20 \pm 0.12$ & $51.30 \pm 0.35$ & $51.41 \pm 0.22$ \\
\hline C18:2 & $8.82 \pm 0.79$ & $8.03 \pm 1.07$ & $55.80 \pm 0.63$ & $53.95 \pm 0.29$ & $14.56 \pm 0.78$ & $13.28 \pm 0.38$ & $32.48 \pm 0.70$ & $31.30 \pm 0.27$ \\
\hline \multirow[t]{2}{*}{ C18:3 } & $1.12 \pm 0.41$ & $0.95 \pm 0.25$ & $1.86 \pm 0.46$ & $1.65 \pm 0.15$ & $1.28 \pm 0.46$ & $1.01 \pm 0.19$ & $1.48 \pm 0.62$ & $1.36 \pm 0.12$ \\
\hline & \multicolumn{2}{|c|}{ Olive oil $+0.02 \%$ BHT } & \multicolumn{2}{|c|}{ Corn oil $+0.002 \%$ BHT } & \multicolumn{2}{|c|}{ Olive-residue oil + $0.02 \%$ BHT } & \multicolumn{2}{|c|}{ Mixture oil (50:50 olive oil and corn oil) $+0.02 \% \mathrm{BH}$} \\
\hline C16:0 & $11.19 \pm 0.34$ & $11.54 \pm 0.45$ & $10.63 \pm 0.68$ & $11.58 \pm 0.31$ & $10.10 \pm 0.76$ & $10.91 \pm 0.41$ & $11.06 \pm 0.99$ & $11.68 \pm 0.42$ \\
\hline C16:1 & $1.22 \pm 0.72$ & $1.18 \pm 0.28$ & - & - & $0.70 \pm 0.39$ & $0.66 \pm 0.10$ & $0.64 \pm 0.36$ & $0.59 \pm 0.24$ \\
\hline C18:0 & $2.33 \pm 0.59$ & $2.53 \pm 0.33$ & $1.67 \pm 0.31$ & $2.27 \pm 0.17$ & $2.70 \pm 0.70$ & $3.11 \pm 0.33$ & $2.12 \pm 0.91$ & $2.47 \pm 0.09$ \\
\hline C18:1 & $74.53 \pm 0.82$ & $74.68 \pm 0.51$ & $29.20 \pm 0.67$ & $29.29 \pm 0.36$ & $70.02 \pm 0.83$ & $70.17 \pm 0.20$ & $51.30 \pm 0.36$ & $51.39 \pm 0.31$ \\
\hline C18:2 & $8.82 \pm 0.79$ & $8.14 \pm 0.35$ & $55.80 \pm 0.63$ & $54.07 \pm 0.27$ & $14.56 \pm 0.78$ & $13.30 \pm 0.39$ & $32.48 \pm 0.70$ & $31.36 \pm 0.24$ \\
\hline C18:3 & $1.12 \pm 0.41$ & $0.96 \pm 0.17$ & $1.86 \pm 0.46$ & $1.69 \pm 0.06$ & $1.28 \pm 0.46$ & $1.07 \pm 0.22$ & $1.48 \pm 0.62$ & $1.34 \pm 0.21$ \\
\hline
\end{tabular}


Correlation between analytical methods during heating. Correlation coefficients ( $r$ ) between each pair of analytical values were calculated to study the degree of association between two characteristics taken under consideration. The highest correlations were obtained between free fatty acids and polar compounds $(r=0.963)$, and between polar compounds and viscosity $(r=0.953)$.

All the analytical methods used in this study are indicators of the state of oil deterioration. Although none parameter can judge heating life adequately in all situations. The changes in characteristics and composition of used oils showed that olive oil and mixture oil was more stable during heating than olive residue oil and corn oil, as expected. This work also confirmed that antioxidants BHA and BHT did not prevent deterioration of used oils during heating, which has also been observed by other workers in different oils (Augustin and Berry, 1983; Boskou, 1988). In contrast to our results Fritch (1981) reported that $\mathrm{BHA}$ provided significant protection in heated palm olein.

\section{REFERENCES}

Abdel-Aal, M.H. and Karara, H.A. (1986). Changes in corn oil during deep-fat frying of foods. Lebensm. Wiss Technol. 19, 323-327.

Al-Harbi, M.M. and Al-Kabtani, H.A. (1993). Chemical and biological evaluation of discarded frying palm oil commercial restaurants. Food Chemistry, 48, 395-401.

Alim, H. and Morton, I.D. (1974). Oxidation in foodstuffs fried in edible oils in International Congress of Food Science and Technology, Vol 6, pp. 345-556. Madrid, Spain.

AOCS (1978). Official and Tentative Methods, the American Oil Chemist's Society, $3^{\text {rd }}$ ed., Champain, IL., USA.

Augustin, M.A. and Berry, S.K. (1983). Efficacy of the antioxidants $\mathrm{BHA}$ and $\mathrm{BHT}$ in palm olein during heating and frying. JAOCS, 60, 1520-1522.

Boskou, D. (1988). Stability of frying oils in Frying of Food: Principles, changes, new approaches, pp. 174-182. Varela, G., Bender, A.E. and Morton, I.D. (Ed), Ellis Horwood Series in Food Science and Technology, Chichester, England.

British Standards Methods of Analysis. Fats and Oils, part 1, Physical Methods, Section 1.8 (1976).

Chang, S. S., Peterson, R. J. and Ho, C.T. (1978). Chemistry of deep fat frying in Lipids as a source of flavour. Supran, M. K., (Ed.), American Chemical Society, USA.

Fritch, C.W. (1981). Measurements of frying fat deterioration: A brief review. Journal of the American Oil Chemists'Society, 58, 746-750.

Gutiérrez, R., González, O. and Dobarganes, M.C. (1988). Analytical procedures for the evaluation of used frying fats. In: Frying of Food: Principles, Changes, New Approaches. pp. 141-154. Varela, G., Bender, A. E. and Morton, I. D. (Ed.), VCH Publishers Ltd., London.

International Union of Pure and Applied Chemistry (IUPAC). (1987). Standard methods for the analysis of oils, fats and derivatives, 7th revised and enlarged edn, pp. 212-213 Paquot, C. and Hautfenne, A. (Ed), Blackwell Scientific Publication, London.

Landers, R.E. and Rathman, D.N. (1981). Vegetable oils: Effects of processing, storage and use on nutritional values. Journal of the American Oil Chemists'Society, 58, 255-259.

Lea, C.H. (1952). Methods for determination peroxides in lipids. Journal of the Science of Food and Agriculture, 3, 586-594.

Lea, C.H. (1960). On the antioxidant activities of the tocopherols. Il-Influence of substrate, temperature and level of oxidation. Journal of Science of Food and Agriculture, 11, 212-215.

Miyagawa, K., Hirai, K. and Takezoe, R. (1991). Tocopherol and fluorescence levels in deep-frying oil and their measurement for oil assessment. Journal of the American Oil Chemists Society, 68, 163-166.

Morton, I.D. and Chidley, J.E. (1988). Methods and equipment in frying in Frying Food: Principles, Changes, New Approaches, pp. 37-5Varela, G., Bender, A.E. and Morton, I.D. (Ed.), Ellis Horwood, London1.

Pearsons, D. (1981). Chemical Analysis of Foods. $8^{\text {th }}$ Ed. , pp. 520-547. Elan, H., Kird, R. S. and Sawyer, R. (Ed.), Churchill Livingstone, Edinburgh, Britain.

Peled, N., Gutfinger, T. and Letan, A. (1975). Effect of water and BHT on stability of cottonseed oil during frying. Journal of Food Science and Agriculture, 26, 1655-1668.

Perkins, E.G. (1967). Non-volatile decomposition products in heated fats and oils. Food Technology, 21, 611-616.

Sonntag, N.O.V. (1979). Composition and characteristics of individual fats and oils in Bailey's Industrial Oil and Fat Products, Vol. 11. Swern, D. (Ed.), $4^{\text {th }}$ Ed., pp. 389-398. John Wiley and Sons, New York.

Tsaknis, J. (1991). Quality changes of olive oil and other selected vegetable oil during frying. MPhil Thesis, University of Humberside.

Tsaknis, J., Lalas, S., Hole, M., Smith, G. and Tychopoulos, V. (1998). An HPLC rapid method of determining malonodialdehyde (MDA) for evaluation of rancidity in edible oils. Analyst, 123, 325-327.

Tsaknis, J., Spiliotis, V., Lalas, S., Gergis, V. and Dourtoglou, V. (1999). Quality changes of Moringa Oleifera, variety Mbololo of Kenya seed oil during frying. J. Agric. Food Chem. 47, 4495-4499.

Tyagi, V. K. and Vasishtha, A. K. (1996). Changes in characteristics and composition of oils during deep fat frying. JAOCS, 73, 499-506. 